\title{
Intraoperative thermal insulation in off-pump coronary artery bypass grafting surgery: a prospective, double blind, randomized controlled, single-center study
}

\author{
Lin Jin, Xiaodan Han, Ying Yu, Liying Xu, Huilin Wang, Kefang Guo \\ Department of Anesthesia, Zhongshan Hospital, Fudan University, Shanghai, China \\ Contributions: (I) Conception and design: L Jin, K Guo; (II) Administrative support: Y Yu, L Xu, H Wang; (III) Provision of study materials or \\ patients: L Jin, X Han, Y Yu, L Xu, H Wang; (IV) Collection and assembly of data: L Jin, X Han, K Guo; (V) Data analysis and interpretation: L Jin, \\ K Guo; (VI) Manuscript writing: All authors; (VII) Final approval of manuscript: All authors. \\ Correspondence to: Kefang Guo. Department of Anesthesia, Zhongshan Hospital, Fudan University, Xuhui District, No. 1609, Xietu Road, Shanghai, \\ China. Email: dr_guokefang@163.com.
}

\begin{abstract}
Background: About $50 \%$ patients who underwent off-pump coronary artery bypass grafting (OPCAB) experienced perioperative hypothermia. Pre-warming and intraoperative infusion of amino acid injection are the most popular perioperative insulation measures in recent years, but neither of them can completely prevent intraoperative hypothermia. The objective is to investigate the effect of preoperative warming and/ or intraoperative infusion of amino acid injection on body temperature in patients undergoing OPCAB.

Methods: A prospective, double blind, randomized controlled, single-center study. Seventy-two patients were randomly divided into 4 groups: control group, pre-warming group, amino-acid group and multi-mode group. Pre-warming and multi-mode group were pre-heated with warming blankets and forced-air warming system before induction. After that, amino-acid and multi-mode group were infused with 18-amino acid solution. The perioperative temperature and complications were monitored.

Results: The temperature of control and amino-acid group decreased significantly, but amino-acid group recovered to preoperative level faster. The temperature of pre-warming group was stable, and that in multimode group increased at $60 \mathrm{~min}$ after the start of surgery. There was a significant difference in temperature at each time, and no difference in the incidence of complications between the groups.

Conclusions: Preoperative warming and/or intraoperative infusion of amino acid injection can effectively reduce hypothermia in OPCAB surgery. Pre-warming before anesthesia is more effective, and the combination of the two methods has the best effect.
\end{abstract}

Keywords: Perioperative hypothermia; pre-warming; amino acid therapy; off-pump coronary artery bypass grafting (OPCAB)

Submitted Dec 23, 2019. Accepted for publication Jul 24, 2020.

doi: $10.21037 /$ atm-19-4571

View this article at: http://dx.doi.org/10.21037/atm-19-4571

\section{Introduction}

Coronary heart disease is one of the leading causes of death in the world. According to the WHO's World Health Statistics Report 2018, about 17.9 million people died from cardiovascular disease globally in 2016. Surgical myocardial revascularization continues to be the standard of care for patients with 3-vessel or left main coronary artery disease, estimated 800,000 people undergo the surgery worldwide each year (1).

Off-pump coronary artery bypass grafting (OPCAB) was popularized during the late 1990s and the following decade and has become a routine method for coronary revascularization. With "fast track" anesthesia, early extubation has also become the target of such patient's 
perioperative management (2). To achieve this goal, Kaplan Heart Anesthesiology recommends keeping the patient's temperature stable (above $35^{\circ} \mathrm{C}$, and thermal insulation device is recommended to maintain the patient's normal body temperature) (3). According to statistics, about 50\% patients who underwent $\mathrm{OPCAB}$ experienced perioperative hypothermia, and about $10 \%$ patients suffered their body temperature dropped below $34.5{ }^{\circ} \mathrm{C}$ (4). The side effects of perioperative hypothermia have been widely recognized. It causes discomfort to patients, reduces the quality of recovery, changes pharmacokinetics and pharmacodynamics, increases oxygen consumption and cardiovascular system complications, reduces body immunity, causes coagulation dysfunction and so on (5-7). Bleeding, infection, and cardiac events significantly increase patient mortality for patients undergoing coronary revascularization.

However, maintaining the body temperature of OPCAB patients is not an easy task.

Currently, the commonly used thermal insulation devices include the forced-air warming system, the warming blanket, and the warmed intravenous fluids. In OPCAB operation, the effective heating position of the forced-air warming system and the heating blanket is only the back, the head and the neck with small heating area and poor preservation. And the infusion principle avoiding the capacity overload limits the effect of liquid heating devices (8).

Hypothermia still occurs, despite several studies have proved that preoperative warming can reduce the incidence of intraoperative hypothermia (9-12). Not only that, for patients with heart disease, the conventional preoperative medication has further lowered the patient's central body temperature, and short-term warming treatment before surgery does not completely restore the body temperature. Moreover, oral premedication on the ward lowered core temperature significantly. This drop in core temperature cannot be offset by a short period of active prewarming (13).

Intraoperative infusion of amino acid injection is also one of the most popular perioperative insulation measures in recent years (14-16). Some studies have proved the effectiveness and safety. However, the conclusions of various studies are not completely consistent. A recent meta-analysis of 565 patients in 14 studies suggested that intraoperative amino acid infusion increased body temperature by $0.5^{\circ} \mathrm{C}$, but this difference was only statistically significant at the end of the operation, but not at other time points. This means that intraoperative amino acid infusion alone does not maintain the normal range of temperature throughout the operation. It is also unclear whether amino acids confer any other benefits or harms, as high-quality data about these outcomes are lacking. Therefore, animal experiments and clinical studies of intraoperative amino acid infusion are still emerging (17-19).

From the perspective of clinical operation, pre-warming and intra-operative amino acid infusion can be used for OPCAB surgery; from the perspective of effectiveness, prewarming before surgery is more helpful to maintain the body temperature in the early stage of the operation, and the intra-operative amino acid infusion is better during the later stage to the end of the operation. Neither of them can completely prevent intraoperative hypothermia. As far as we know, there has been no research on the combination of pre-warming and of amino acids infusion for maintaining perioperative body temperature. Therefore, we hope to conduct a well-designed study on perioperative thermal insulation of cardiac surgery. Therefore, we hope to conduct a well-designed study of cardiac surgery, and combine the advantages of the above two complements, in order to achieve the best thermal insulation effect.

The purpose of this study was to investigate the thermal insulation effect of the above two measures in OPCAB surgery, in order to optimize the intraoperative thermal insulation strategy and provide safer and more comfortable anesthesia management for OPCAB surgery.

We present the following article in accordance with the CONSORT reporting checklist (available at http://dx.doi. org/10.21037/atm-19-4571).

\section{Methods}

The study was conducted in accordance with the Declaration of Helsinki (as revised in 2013) and was approved by the Ethics Committee of Zhongshan Hospital Affiliated to Fudan University (ethics approval number: B2016-020). It was designed as a prospective, randomized, double-blind, controlled clinical study.

\section{Participant inclusion}

The inclusion criteria were patients who underwent elective OPCAB surgery between the ages of 18 and 80 without gender limitation, and the body mass index (BMI) was $18-31 \mathrm{~kg} / \mathrm{m}^{2}$. All informed consent forms of these patients were signed. Those who do not cooperate or cannot communicate, or had previous respiratory disease, liver and kidney dysfunction, poor glycemic control, and preoperative central body temperature above $37.5^{\circ} \mathrm{C}$ were excluded. Patients with intraoperative intra-aortic balloon 
pulsation (IABP) or changes in extracorporeal circulation bypass were excluded. The study was designed blindly with researchers' responsibility as follows: Researcher 1, knowing the grouping situation, performing anesthesia and perioperative management; Researcher 2, not recognize the grouping situation, full-time evaluation of perioperative body temperature and other evaluation indicators. Seventy two patients were enrolled and no one was excluded.

\section{Clinical treatment programs}

All enrolled patients were routinely preoperative fasted and banned drinking. Oral administration of tafil $0.4 \mathrm{mg}$ and famotidine $20 \mathrm{mg}$ was given in preoperative evening and $1 \mathrm{~h}$ preoperation. Electrocardiogram (ECG) monitoring was given immediately after the patient entered the operation room, and continuous central venous pressure and arterial pressure monitoring with central venous catheterization and radial artery catheterization was performed. Sufentanil $0.2-0.3 \mu \mathrm{g} / \mathrm{kg}$, propofol target-controlled infusion (TCI) $2-3 \mu \mathrm{g} / \mathrm{mL}$, and rocuronium $0.9 \mathrm{mg} / \mathrm{kg}$ were used for anesthesia induction. Intubation mechanical ventilation with adjustment of ventilator parameters [intermittent positive pressure ventilation (IPPV) mode, tidal volume $7-8 \mathrm{~mL} / \mathrm{kg}$, respiratory rate 10 times $/ \mathrm{min}$ ] to maintain endtidal carbon dioxide $35 \pm 5 \mathrm{mmHg}$. Sevoflurane minimum alveolar concentration (MAC) 0.6-1.0, propofol plasma TCI $1-2 \mu \mathrm{g} / \mathrm{mL}$, and dexmedetomidine $0.4 \mu \mathrm{g} / \mathrm{kg} / \mathrm{h}$ were used for anesthesia maintaining with bispectral index (BIS) 40-60. Sufentanil $0.05-0.1 \mu \mathrm{g} / \mathrm{kg}$ per time with rocuronium $0.3 \mathrm{mg} / \mathrm{kg}$ (first time) or $0.2 \mathrm{mg} / \mathrm{kg}$ per time was added if necessary. Rocuronium was stopped $30 \mathrm{~min}$ before the end of operation. At the end of the operation, sevoflurane and propofol were stopped and an analgesia pump was started (sufentanil $1 \mu \mathrm{g} / \mathrm{mL}$, background dose $0.5-1 \mathrm{~mL} / \mathrm{h}$, bolus dose 3-4 mL/time, locking time $10 \mathrm{~min}$ ). Patients who met extubation indications were extubated (extubation indications: consciousness recovered; active cough and swallowing reflexes; residual effects of muscle relaxants reversed; fine spontaneous breathing frequency and normal tidal volume; normal arterial blood gas analysis; stable circulatory function and the heart rhythm; normal urine volume; stable internal environment; complete surgical hemostasis).

\section{Experiment design}

After entering the operating room, the patients were randomly divided into control group (Control G), prewarming group (Pre $G$ ), amino acid group (AA G) and multimode group (Mul G), with 18 cases in each group. The operating room temperature was maintained at $22-24{ }^{\circ} \mathrm{C}$. All patients were infused with $8 \mathrm{~mL} / \mathrm{kg} / \mathrm{h}$ sodium lactate Ringer's solution from $30 \mathrm{~min}$ before induction of anesthesia $(20,21)$ to postoperative extubation, and intraoperative blood loss was 1:1 supplemented using 6\% hydroxyethyl starch 130/0.4, and blood or blood products were given if necessary. All infusion fluids were heated to $40-42{ }^{\circ} \mathrm{C}$. Control G: after induction, the temperaturechanging warming blanket $\left(42^{\circ} \mathrm{C}\right)$ and the forced-air warming system $\left(42^{\circ} \mathrm{C}\right)$ were used to heat the patient's back and head and neck; Pre G: the temperature-changing warming blanket $\left(42^{\circ} \mathrm{C}\right)$ and the forced-air warming system $\left(42^{\circ} \mathrm{C}\right)$ were used after entering the operating room to preheated the patient's body for $30 \mathrm{~min}$, which continued after induction to heat the patient's back and head and neck; AA G: after induction, the temperature-changing warming blanket $\left(42^{\circ} \mathrm{C}\right)$ and the forced-air warming system $\left(42{ }^{\circ} \mathrm{C}\right)$ were used to heat the patient's back and head and neck with infusion of 18-amino acid complex $4 \mathrm{~kJ} / \mathrm{kg} / \mathrm{h}(2.4 \mathrm{~mL} / \mathrm{kg} / \mathrm{h})$ which intraoperative sodium lactate Ringer's solution changed to $5.6 \mathrm{~mL} / \mathrm{kg} / \mathrm{h}$ until the end of the operation; $\mathrm{Mul}$ G: the temperature-changing warming blanket $\left(42{ }^{\circ} \mathrm{C}\right)$ and the forced-air warming system $\left(42^{\circ} \mathrm{C}\right)$ were used after entering the operating room to pre-heated the patient's body for $30 \mathrm{~min}$, which continued after induction to heat the patient's back and head and neck, and infusion of 18-amino acid complex $4 \mathrm{~kJ} / \mathrm{kg} / \mathrm{h}(2.4 \mathrm{~mL} / \mathrm{kg} / \mathrm{h})$ was given at entering, which intraoperative sodium lactate Ringer's solution changed to $5.6 \mathrm{~mL} / \mathrm{kg} / \mathrm{h}$ until the end of the operation.

Once the patient's core body temperature exceeded $37.5^{\circ} \mathrm{C}$, the forced-air warming system, the temperature change blanket, the liquid warming device and the amino acid injection would be sequentially stopped. Insulin was used to maintain intraoperative blood glucose $\leq 10 \mathrm{mmol} / \mathrm{L}$.

\section{Data collection}

After the patient entered the operating room, the sublingual body temperature $\left(\mathrm{T}_{\text {base }}\right)$ was measured with mercury body temperature agent. After the induction, the esophageal temperature probe was placed to measure the temperature of the nasopharynx ( $\mathrm{T}_{\text {induc }}$ ). The nasopharyngeal body temperature was recorded every $30 \mathrm{~min}$ during the operation [Infinity Omega monitor, Dräger medical equipment (Shanghai) Co., Ltd.] $\left(\mathrm{T}_{0}-\mathrm{T}_{6}\right)$ to the end of surgery $\left(\mathrm{T}_{\text {end }}\right)$, 
Table 1 Comparison of general conditions and basic conditions of surgery

\begin{tabular}{|c|c|c|c|c|c|c|}
\hline Characteristics & Control G (n=18) & Pre $G(n=18)$ & AA G $(n=18)$ & Mul G $(n=18)$ & $\mathrm{F}$ & $\mathrm{P}$ \\
\hline Age (years) & $63.7(59.8-67.5)$ & $65.3(62.5-68.1)$ & $60.8(56.8-64.8)$ & $63.2(61.3-65.1)$ & 0.948 & 0.423 \\
\hline Weight (kg) & $65.1(62.1-68.0)$ & 70.5 (66.7-74.3) & $67.4(63.7-71.0)$ & 69.4 (65.8-72.9) & 2.072 & 0.112 \\
\hline Height (cm) & $166.3(163.1-169.5)$ & $165.6(162.8-168.4)$ & $168.3(165.8-170.7)$ & $167.6(165.5-169.8)$ & 0.952 & 0.421 \\
\hline Anesthesia time (min) & 219 [198-239] & 226 [207-245] & 243 [222-263] & 232 [210-254] & 1.112 & 0.351 \\
\hline Operation time (min) & 200 [181-219] & 207 [189-226] & 224 [204-244] & 216 [194-238] & 1.219 & 0.310 \\
\hline
\end{tabular}

Control G: control group; Pre G: pre-warming group; AA G: amino acid group; Mul G: multi-mode group. ASA, American Society of Anesthesiologists.

and $1 \mathrm{~h}\left(\mathrm{~T}_{7}\right), 2 \mathrm{~h}\left(\mathrm{~T}_{8}\right)$ and $4 \mathrm{~h}\left(\mathrm{~T}_{9}\right)$ after surgery. Liver and kidney function, intraoperative insulin dose and blood glucose were recorded before and after surgery, and the incidence of cardiac events, wound infection and other complications were recorded and compared between the groups.

\section{Statistical analysis}

Statistical analysis was applied by SPSS 19.0. The measurement data was expressed as mean ( $95 \%$ confidence interval). One-way analysis of variance was used for comparison between normal distribution data sets. Repeated measurement data variance analysis was used for comparison data sets in the group. The rank sum test was used for comparison between non-normal distribution data sets. The count data was represented by the median (interquartile range). Chi-square test was used for comparison between groups. $\mathrm{P}<0.05$ was set as statistically significant.

\section{Results}

\section{Patient baseline characteristics}

There were no significant differences in the baseline characteristics of four groups, which include age, gender, height, weight and the American Society of Anesthesiologists (ASA) classification, and no significant differences in the basic conditions of surgery including anesthesia time and operation time (Table 1).

\section{Perioperative body temperature}

The basal body temperature of the four groups was similar, and there was no significant difference between the groups $(\mathrm{P}=0.848)$. The body temperature of Control $\mathrm{G}$ and $\mathrm{AA} G$ decreased significantly from the baseline value since the start of surgery (Control $G$ from $T_{0}$ to $T_{9}, P<0.05$; AA G from $T_{\text {induc }}$ to $\left.T_{6}, P<0.05\right)$. However, the body temperature of AA $\mathrm{G}$ recovered quickly to the preoperative level after decreasing, and it was higher than the baseline value at $4 \mathrm{~h}$ postoperatively $(\mathrm{P}<0.05)$; the body temperature of Pre $\mathrm{G}$ at $T_{\text {induc }}$ was higher than that before surgery $(\mathrm{P}<0.05)$, and then remained at the same level as the base value with a small change; the body temperature of Mul G at $T_{\text {induc }}$ and $\mathrm{T}_{6}-\mathrm{T}_{9}$ was significantly higher than the baseline, and the differences was statistically significant $(\mathrm{P}<0.05)$ (Figure 1). The comparison between groups was observed from the time of induction of anesthesia to the end of surgery, which suggested that the body temperature of Pre G and Mul G patients was significantly higher than that of Control $G$ and $A A G$ at each time point $(\mathrm{P}<0.05)$. From the end of the operation to $4 \mathrm{~h}$ after surgery, there was a statistically significant difference between Control G and Pre G, AA G or Mul G at each time point (Table 2).

\section{Dynamic changes in blood glucose and hepatorenal function}

Postoperative blood glucose levels of all four groups were higher than preoperative (Table 3). The differences in Control G, Pre G and AA G were statistically significant: Control G 6.32 (5.8-6.9) $\mathrm{mmol} / \mathrm{L}$ preoperative and 7.66 (6.9-8.4) $\mathrm{mmol} / \mathrm{L}$ postoperative, $\mathrm{P}=0.025$; Pre G 6.74 (6.07.5) $\mathrm{mmol} / \mathrm{L}$ preoperative, $7.90(7.2-8.6) \mathrm{mmol} / \mathrm{L}$ postoperative, $\mathrm{P}=0.022$; AA G $6.36(5.9-6.8) \mathrm{mmol} / \mathrm{L}$ preoperative, 7.73 (7.0-8.5) $\mathrm{mmol} / \mathrm{L}$ postoperative, $\mathrm{P}=0.001 ; \mathrm{Mul} \mathrm{G} 6.93$ 


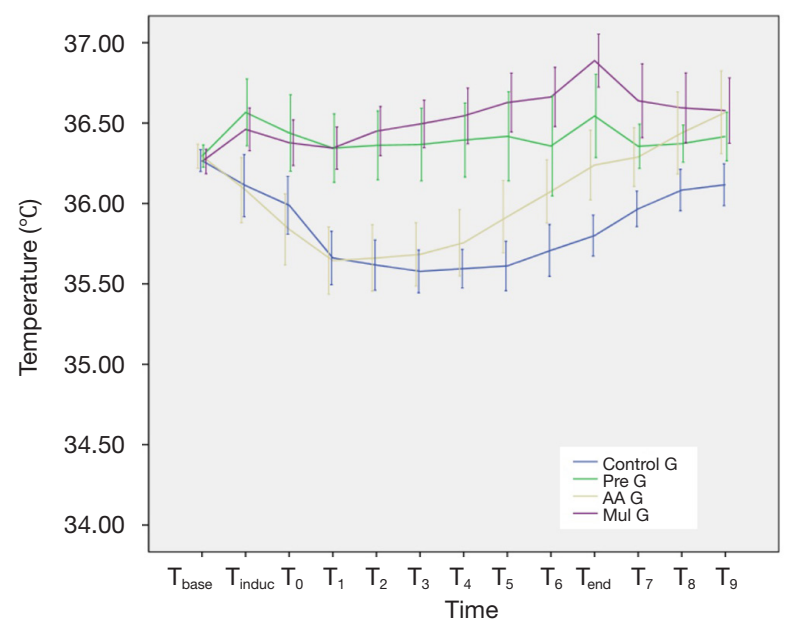

Figure 1 Comparison of perioperative core body temperature. The body temperature of Control $G$ from $T_{0}$ to $T_{9}$ was significantly lower than $\mathrm{T}_{\text {base }}, \mathrm{P}<0.05$. The body temperature of AA $\mathrm{G}$ from $\mathrm{T}_{\text {induc }}$ to $\mathrm{T}_{6}$ was significantly lower than $\mathrm{T}_{\text {base }}, \mathrm{P}<0.05$; and significantly higher than $\mathrm{T}_{\text {base }}$ at $\mathrm{T}_{9}, \mathrm{P}<0.05$. The body temperature of Pre $\mathrm{G}$ at $\mathrm{T}_{\text {induc }}$ was significantly higher than $\mathrm{T}_{\text {base }}, \mathrm{P}<0.05$. The body temperature of $M u l \mathrm{G}$ at $\mathrm{T}_{\text {induc }}$ and $\mathrm{T}_{6}-\mathrm{T}_{9}$ was significantly higher than $\mathrm{T}_{\text {base }}, \mathrm{P}<0.05$. Tbase: preoperative baseline; $\mathrm{T}_{\text {induc }}$ immediately after induction of anesthesia; $\mathrm{T}_{0}$ : immediate at the start surgery; $\mathrm{T}_{1}: 30 \mathrm{~min}$ after the start of surgery; $\mathrm{T}_{2}: 60 \mathrm{~min}$ after the start of surgery; $\mathrm{T}_{3}: 90 \mathrm{~min}$ after the start of surgery; $T_{4}: 120 \mathrm{~min}$ after the start of surgery; $\mathrm{T}_{5}: 150 \mathrm{~min}$ after the start of surgery; $\mathrm{T}_{6}: 180$ min after the start of surgery; $\mathrm{T}_{\text {end }}:$ immediately at the end of the surgery; $\mathrm{T}_{7}: 1 \mathrm{~h}$ after surgery; $\mathrm{T}_{8}: 2 \mathrm{~h}$ after surgery; $\mathrm{T}_{9}: 4 \mathrm{~h}$ after surgery. Control G: control group; Pre $\mathrm{G}$ : pre-warming group; AA G: amino acid group; Mul G: multi-mode group.

Table 2 Comparison of perioperative core body temperature $\left({ }^{\circ} \mathrm{C}\right)$

\begin{tabular}{|c|c|c|c|c|c|c|}
\hline Time point & Control G $(n=18)$ & Pre $G(n=18)$ & AA $G(n=18)$ & Mul G $(n=18)$ & $\mathrm{F}$ & $\mathrm{P}$ \\
\hline $\mathrm{T}_{\text {induc }}$ & $36.1(35.9-36.3)^{\# \S}$ & $36.6(36.4-36.8)^{\star^{\dagger}}$ & $36.1(35.9-36.3)^{\# \S}$ & $36.5(36.3-36.6)^{\star^{\dagger}}$ & 7.627 & $<0.001$ \\
\hline $\mathrm{T}_{0}$ & $36.0(35.8-36.2)^{\# \S}$ & $36.4(36.2-36.7)^{\star \dagger}$ & $35.9(35.6-36.1)^{\# \S}$ & $36.4(36.2-36.5)^{\star^{\dagger}}$ & 9.665 & $<0.001$ \\
\hline $\mathrm{T}_{1}$ & $35.7(35.5-35.8)^{\# \S}$ & $36.3(36.1-36.6)^{\star \dagger}$ & $35.6(35.4-35.9)^{\# \S}$ & $36.3(36.2-36.5)^{\star \dagger}$ & 21.231 & $<0.001$ \\
\hline $\mathrm{T}_{3}$ & $35.6(35.5-35.7)^{\# \S}$ & $36.4(36.1-36.6)^{\star^{\dagger}}$ & $35.7(35.5-35.9)^{\# \S}$ & $36.5(36.3-36.6)^{\star^{\dagger}}$ & 29.950 & $<0.001$ \\
\hline $\mathrm{T}_{4}$ & $35.6(35.5-35.7)^{\# \S}$ & $36.4(36.1-36.6)^{\star \dagger}$ & $35.8(35.5-36.0)^{\# \S}$ & $36.5(36.4-36.7)^{\star \dagger}$ & 27.773 & $<0.001$ \\
\hline $\mathrm{T}_{5}$ & $35.6(35.5-35.8)^{\# \S}$ & $36.3(36.1-36.7)^{\star \dagger}$ & $35.9(35.7-36.1)^{\# \S}$ & $36.6(36.4-36.8)^{\star \dagger}$ & 21.111 & $<0.001$ \\
\hline $\mathrm{T}_{6}$ & $35.7(35.5-35.9)^{\dagger \# \S}$ & $36.4(36.0-36.7)^{\star}$ & $36.1(35.9-36.3)^{\star \S}$ & $36.7(36.5-36.8)^{\star^{\dagger}}$ & 14.877 & $<0.001$ \\
\hline $\mathrm{T}_{8}$ & $36.1(36.0-36.2)^{\# \S}$ & $36.4(36.3-36.5)^{\star}$ & $36.4(36.2-36.7)$ & $36.6(36.4-36.8)^{\star}$ & 5.708 & 0.002 \\
\hline $\mathrm{T}_{9}$ & $36.1(36.0-36.2)^{\#+\S}$ & $36.4(36.3-36.6)^{*}$ & $36.6(36.3-36.8)^{\star}$ & $36.6(36.4-36.8)^{\star}$ & 5.558 & 0.002 \\
\hline
\end{tabular}

*, compared with Control G, P<0.05; ", compared with Pre G, P<0.05; ${ }^{\dagger}$, compared with AA G, P<0.05; ${ }^{\S}$, compared with Mul G, P<0.05. $T_{\text {base }}$ : preoperative baseline; $T_{\text {induc }}$ : immediately after induction of anesthesia; $T_{0}$ : immediate at the start surgery; $T_{1}: 30$ minutes after the start of surgery; $T_{2}: 60$ minutes after the start of surgery; $T_{3}: 90$ minutes after the start of surgery; $T_{4}: 120$ minutes after the start of surgery; $\mathrm{T}_{5}: 150 \mathrm{~min}$ after the start of surgery; $\mathrm{T}_{6}: 180 \mathrm{~min}$ after the start of surgery; Tend: immediately at the end of the surgery; $\mathrm{T}_{7}: 1 \mathrm{~h}$ after surgery; $\mathrm{T}_{8}: 2 \mathrm{~h}$ after surgery; $\mathrm{T}_{9}: 4 \mathrm{~h}$ after surgery. Control G: control group; Pre G: pre-warming group; AA G: amino acid group; Mul G: multimode group. 
Table 3 Comparison of glucose metabolism

\begin{tabular}{|c|c|c|c|c|c|c|}
\hline Variables & Control G $(n=18)$ & Pre $G(n=18)$ & AA G $(n=18)$ & Mul G (n=18) & $\mathrm{F}$ & $\mathrm{P}$ \\
\hline \multicolumn{7}{|l|}{ Glucose (mmol/L) } \\
\hline Preoperative & $6.32(5.8-6.9)$ & $6.74(6.0-7.5)$ & $6.36(5.9-6.8)$ & $6.93(6.0-7.8)$ & 0.861 & 0.466 \\
\hline Postoperative & $7.66(6.9-8.4)$ & $7.90(7.2-8.6)$ & $7.73(7.0-8.5)$ & $7.77(7.1-8.4)$ & 0.090 & 0.965 \\
\hline $\mathrm{P}$ & 0.025 & 0.022 & 0.001 & 0.149 & & \\
\hline
\end{tabular}

Table 4 Evaluation of safety indicators

\begin{tabular}{|c|c|c|c|c|c|c|}
\hline Variables & Control G (n=18) & Pre $G(n=18)$ & AA G $(n=18)$ & Mul G (n=18) & $\mathrm{F}$ & $\mathrm{P}$ \\
\hline Preoperative & $21.8(18.1-25.6)$ & $24.6(17.0-32.2)$ & $24.5(16.3-32.7)$ & $31.3(22.5-40.0)$ & 1.341 & 0.268 \\
\hline Postoperative & $37.1(23.1-51.1)$ & 23.7 (16.3-31.1) & $40.2(27.2-53.3)$ & $35.6(24.5-46.7)$ & 1.720 & 0.171 \\
\hline $\mathrm{P}$ & 0.049 & 0.812 & 0.011 & 0.432 & & \\
\hline Preoperative & 20.5 (18.1-22.9) & $19.1(16.0-22.3)$ & $20.6(16.4-24.7)$ & 23.6 (19.3-27.9) & 1.209 & 0.313 \\
\hline Postoperative & $34.2(23.7-44.7)$ & $26.0(19.2-32.8)$ & $36.5(26.4-46.7)$ & $27.1(22.0-32.2)$ & 1.682 & 0.179 \\
\hline $\mathrm{P}$ & 0.015 & 0.042 & 0.001 & 0.114 & & \\
\hline \multicolumn{7}{|l|}{ BUN (mmol/L) } \\
\hline$P$ & 0.030 & 0.010 & 0.003 & $<0.001$ & & \\
\hline \multicolumn{7}{|l|}{$\mathrm{SCr}(\mu \mathrm{mol} / \mathrm{L})$} \\
\hline Preoperative & 81.7 (74.2-89.1) & $74.4(66.2-82.6)$ & $74.4(65.7-83.1)$ & 87.9 (79.4-96.4) & 2.777 & 0.048 \\
\hline Postoperative & 98.3 (84.8-111.9) & 87.1 (75.6-98.5) & $87.8(75.9-99.8)$ & 93.6 (85.3-101.9) & 0.951 & 0.421 \\
\hline$P$ & 0.006 & $<0.001$ & 0.103 & 0.073 & & \\
\hline
\end{tabular}

Control G: control group; Pre G: pre-warming group; AA G: amino acid group; Mul G: multi-mode group. ALT, alanine aminotransferase; AST, aspartate aminotransferase; BUN, blood urea nitrogen; $\mathrm{SCr}$, serum creatinine.

(6.0-7.8) $\mathrm{mmol} / \mathrm{L}$ preoperative, $7.77(7.1-8.4) \mathrm{mmol} / \mathrm{L}$ postoperative, $\mathrm{P}=0.149$. There was no significant difference between the groups, and the highest blood glucose was controlled below $10 \mathrm{mmol} / \mathrm{L}$. The intraoperative insulin doses in patients with AA G and Mul G were 14.2 and 18.2 $\mathrm{U}$ respectively, which were significantly higher than Control $\mathrm{G}(\mathrm{P}<0.001)$.

The alanine aminotransferase (ALT) of Control G and AA $\mathrm{G}$ in the first postoperative morning was significantly higher than preoperative $(\mathrm{P}=0.049$ and $\mathrm{P}=0.011)$, and the aspartate aminotransferase (AST) of Control G, Pre G and AA G was significantly higher than preoperative $(\mathrm{P}=0.015, \mathrm{P}=0.042$ and $\mathrm{P}=0.001$ ), blood urea nitrogen (BUN) in each group was significantly higher than preoperative $(\mathrm{P}=0.030, \mathrm{P}=0.010$, $\mathrm{P}=0.003$ and $\mathrm{P}=0.000$ ), and serum creatinine (SCr) of Control $\mathrm{G}$ and Pre $G$ was significantly higher than preoperative $(P=0.006$ and $\mathrm{P}=0.000)$. However, there was no significant difference between the groups before or after the operation (Table 4). 
Table 5 Comparison of complications

\begin{tabular}{|c|c|c|c|c|c|c|}
\hline Outcome variables & Control G (n=18) & Pre $G(n=18)$ & AA G $(n=18)$ & Mul G $(n=18)$ & $\mathrm{F}$ & $\mathrm{P}$ \\
\hline Heart attack (case) & 1 & - & - & - & 2.846 & 1.000 \\
\hline Blood transfusion therapy (case) & 1 & - & - & - & 2.846 & 1.000 \\
\hline Poor wound healing (case) & - & - & 1 & - & 2.846 & 1.000 \\
\hline
\end{tabular}

Control G: control group; Pre G: pre-warming group; AA G: amino acid group; Mul G: multi-mode group.

\section{Prognosis}

The median number of hospital stays in the four groups was 7 days, and there was no significant difference between the groups $(\mathrm{F}=0.000, \mathrm{P}=1.000)$. Postoperative complications: 1 case of myocardial infarction and 1 case of transfusion treatment in control G, 1 case of poor healing and 1 case of cerebral infarction in AA G, and 1 case of cerebral infarction in Mul G. There was no significant difference between the groups (Table 5).

\section{Discussion}

The trend of perioperative body temperature decreasing in patients is regular. For patients with normal preoperative temperature, the core body temperature will be significantly decreased after induction and surgical disinfection. If the intraoperative circulation is stable without obvious bleeding or hemodynamic fluctuations, the temperature slowly rises and gradually approaches the preoperative level after a short time. If the patient's core temperature before surgery is higher, the postoperative body temperature also recovers faster (22).

All kinds of non-cardiac surgery have effective perioperative warming measures (23). However, as is mentioned in the introduction, current OPCAB patients have special surgical position, wide disinfection range, long surgery time, and the warming effect of intraoperative warming measures and liquid heating equipment are limited. In recent years, a number of prospective or retrospective studies have indicated that pre-warming patients for $30 \mathrm{~min}$ with forced-air warming system can effectively reduce the degree of intraoperative hypothermia (9-11). Since the amino acid has the highest nutrient-induced thermogenesis (NIT) which is up to $30 \%$ to $40 \%$ in awake state, amino acids injection during surgery was attempted to improve the perioperative hypothermia caused by anesthesia and surgery. In 2006, exogenous amino acid was used in OPCAB surgery by Japanese researchers Umenai $\mathrm{T}$ and Nakajima $\mathrm{Y}$, with the infusion of $4 \mathrm{~kJ} / \mathrm{kg} / \mathrm{h}$ for $6 \mathrm{~h}$ at $2 \mathrm{~h}$ before induction, which came to the result that the perioperative core body temperature of the test group was about $0.5^{\circ} \mathrm{C}$ higher than that of the control group, while the test group still experienced a lowest temperature of $35.4^{\circ} \mathrm{C}$ at $2 \mathrm{~h}$ after induction (14). For more than 10 years, our research team has conducted a series of studies on the advantages and disadvantages of perioperative infusion of amino acid. It is suggested that intraoperative amino acid infusion is beneficial to maintain normal perioperative temperature in patients undergoing gastrointestinal surgery without increasing the risk of hyperglycemia or causing damage to liver and kidney function. It is safe to prevent perioperative hypothermia (15). In 2008, amino acid was also reported in related applications in OPCAB (16). Therefore, through comprehensive analysis of various current thermal insulation measures, two warming measures of pre-warming and/or amino acid treatments were selected by us to manage perioperative body temperature in patients with OPCAB.

According to this study, we first found that the perioperative changes in body temperature in Control G patients are consistent with the literature (23). Pre-warming the patient with a blanket before anesthesia clearly avoids hypothermia during the whole perioperative process from anesthesia induction to the end of surgery. Intravenous infusing amino acid solution after anesthesia induction can't avoid hypothermia after anesthesia induction, but it significantly helps to shorten the hypothermia duration and to rapidly rise postoperative body temperature to preoperative level. And the combination of the two methods complementary contributes to avoiding the hypothermia process during operation and to maintaining the late intraoperative and postoperative body temperature. Thus, the advantages and disadvantages of using these 
two methods of insulation separately or in combination in OPCAB surgery are obvious. Both Emmert et al. (24) and Jildeh et al. (25) stated that the perioperative hypothermia incidence rate exceeds $50 \%$, and the related risk factors include old age, prolonged induction time, small body surface area, low BMI, regional block, etc., however, time is not a risk factor for perioperative hypothermia. Therefore, for OPCAB patients with good general conditions, the preheating method alone can effectively keep the patient warm. If the patient is high-risked in perioperative hypothermia with factors such as old age and low BMI, intravenously infusion of amino acid can be given along with pre-warming to achieve better warming.

In addition to the analysis of the warming effects of each group of patients, patient's glucose metabolism and perioperative liver and kidney function were also assessed with short-term prognosis.

Different types of amino acid have different effects on glucose, insulin secretion and the demands for exogenous insulin are also different. In this study, the most commonly clinically used 18 -amino acid complex was chosen. It was found that in order to maintain normal blood glucose levels, patients with perioperative infusion of amino acid requires more transfusion of exogenous insulin, which matches the results of our earlier studies $(15,26)$.

Postoperative renal insufficiency is one of the common postoperative complications of OPCAB (27). Compared with 18 -amino acids commonly used in clinical practice, essential amino acid complex (9-AA) and branched-chain amino acid complex (3-AA) are more suitable for patients with renal insufficiency. None of the patients enrolled in this study had any evidence of liver and kidney dysfunction before surgery. The results showed that pre-warming treatment and intravenous infusion of 18-amino acid did not affect the perioperative liver and kidney function. Therefore, 18-amino acid can be safely used for OPCAB patients with normal preoperative liver and kidney function. This conclusion has also been supported by the literature (16).

Hannan et al. (4) retrospectively analyzed 2,294 OPCAB patients in New York in 2007 and found that postoperative respiratory complications in patients with perioperative hypothermia were associated with increased incidence of reoperating, prolonged hospital stay, and increased mortality. A similar conclusion was also reached by a prospective observational study this year: perioperative hypothermia associates with increased blood loss, delayed wound healing, increased surgical-related infection, and prolonged hospital stay (28). The study followed up the short-term prognosis of patients (Table 5). Because the sample size of each group was small, there was no statistical difference between the groups.

\section{Limitations}

There were still some limitations in this study. Firstly, this study was a single-center study with a small sample size. Secondly, while the single surgical team involved in this study was beneficial to reduce the individual differences caused by surgery, it affects the promotion of treatment effects. Thirdly, the study only investigated on the perioperative insulation measures without more in-depth topics such as the warming mechanism. The next research objective includes clinical research and fundamental research. We plan to conduct a multi-center, largesample clinical studies, and adopt prognostic analysis and stratification analysis, so as to identify the optimal thermal insulation method for different characteristic groups. It is also important to do fundamental research of mechanism of amino acid insulation.

\section{Conclusions}

Pre-warming before anesthesia and/or intraoperative infusion of amino acid can effectively reduce the perioperative hypothermia of OPCAB patients. Prewarming before anesthesia has better thermal insulation effect, and 18-amino acid can also be safely temporarily used for OPCAB patients with normal liver and kidney function before surgery. The combination of the two methods can achieve the best thermal insulation effect.

\section{Acknowledgments}

Funding: None.

\section{Footnote}

Reporting Checklist: The authors have completed the CONSORT reporting checklist. Available at http://dx.doi. org/10.21037/atm-19-4571

Data Sharing Statement: Available at http://dx.doi. org/10.21037/atm-19-4571

Conflicts of Interest: All authors have completed the ICMJE uniform disclosure form (available at http://dx.doi. 
org/10.21037/atm-19-4571). The authors have no conflicts of interest to declare.

Ethical Statement: The author is accountable for all aspects of the work in ensuring that questions related to the accuracy or integrity of any part of the work are appropriately investigated and resolved. The study was conducted in accordance with the Declaration of Helsinki (as revised in 2013) and was approved by institutional ethical committee of Zhongshan Hospital, Fudan University (ethics approval number: B2016-020), and informed consent was taken from all the patients.

Open Access Statement: This is an Open Access article distributed in accordance with the Creative Commons Attribution-NonCommercial-NoDerivs 4.0 International License (CC BY-NC-ND 4.0), which permits the noncommercial replication and distribution of the article with the strict proviso that no changes or edits are made and the original work is properly cited (including links to both the formal publication through the relevant DOI and the license). See: https://creativecommons.org/licenses/by-nc-nd/4.0/.

\section{References}

1. Athanasiou T, Saso S, Rao C, et al. Radial artery versus saphenous vein conduits for coronary artery bypass surgery: forty years of competition-which conduit offers better patency? A systematic review and meta-analysis. Eur J Cardiothorac Surg 2011;40:208-20.

2. Chen L, Zheng J, Kong D, et al. Effect of Enhanced Recovery After Surgery Protocol on Patients Who Underwent Off-Pump Coronary Artery Bypass Graft. Asian Nurs Res (Korean Soc Nurs Sci) 2020;14:44-9.

3. Mittnacht AJC, London MJ, Puskas JD, et al. Anesthesia for myocardial revascularization. In: Kaplan JA, Augoustides JGT, Manecke GR, et al. editors. Kaplan's Cardiac Anesthesia: For cardiac and noncardiac surgery. 7th. Edition. Philadelphia, PA: Elsevier, 2017:731-69.

4. Hannan EL, Samadashvili Z, Wechsler A, et al. The relationship between perioperative temperature and adverse outcomes after off-pump coronary artery bypassgraft surgery. J Thorac Cardiovasc Surg 2010;139:1568-75.

5. Putzu M, Casati A, Berti M, et al. Clinical complications, monitoring and management of perioperative mild hypothermia: anesthesiological features. Acta Biomed 2007;78:163-9.
6. Reynolds L, Beckmann J, Kurz A. et al. Perioperative complications of hypothermia. Best Pract Res Clin Anaesthesiol 2008;22: 645-57.

7. Lee BR, Song JW, Kwak YL, et al. The Infuence of Hypothermia on Transfusion Requirement in Patients Who Received Clopidogrel in Proximity to Off-Pump Coronary Bypass Surgery. Yonsei Med J 2014;5 5:224-31.

8. Hofer CK, Worn M, Tavakoli R, et al. Influence of body core temperature on blood loss and transfusion requirements during off-pump coronary artery bypass grafting: a comparison of 3 warming systems. J Thorac Cardiovasc Surg 2005;129:838-43.

9. Lau A, Lowlaavar N, Cooke EM, et al. Effect of preoperative warming on intraoperative hypothermia: a randomized- controlled trial. Can J Anaesth 2018;65:1029-40.

10. de Brito Poveda V, Clark AM, Galvão CM. A systematic review on the effectiveness of prewarming to prevent perioperative hypothermia. J Clin Nurs 2013;22:906-18.

11. Cho YJ, Lee SY, Kim TK, et al. Effect of Prewarming during Induction of Anesthesia on Microvascular Reactivity in Patients Undergoing Off-Pump Coronary Artery Bypass Surgery: A Randomized Clinical Trial. PLoS One 2016;11:e0159772.

12. Zheng XQ, Huang JF, Lin JL, et al. Effects of preoperative warming on the occurrence of surgical site infection: A systematic review and meta-analysis. Int J Surg 2020;77:40-7.

13. Bräuer A, Müller MM, Wetz AJ, et al. Influence of oral premedication and prewarming on core temperature of cardiac surgical patients. BMC Anesthesiol 2019;19:55.

14. Umenai T, Nakajima Y, Sessler DI, et al. Perioperative amino acid infusion improves recovery and shortens the duration of hospitalization after off-pump coronary artery bypass grafting. Anesth Analg 2006;103:1386-93.

15. Zhong J, Ge SJ, Zhuang XF, et al. Effect of intraoperative amino acid infusion on blood glucose under general anesthesia combined with epidural block. Ann Nutr Metab 2012;61:1-6.

16. Moriyama T, Tsuneyoshi I, Omae T, et al. The effect of amino-acid infusion during off-pump coronary arterial bypass surgery on thermogenic and hormonal regulation. J Anesth 2008;22:354-60

17. Gupta N, Bharti SJ, Kumar V, et al. Comparative evaluation of forced air warming and infusion of amino acid-enriched solution on intraoperative hypothermia in patients undergoing head and neck cancer surgeries: A prospective randomised study. Saudi J Anaesth 
2019;13:318-24.

18. Clark-Price SC, Phillips H, Selmic LE, et al. Effect of an intraoperative infusion of amino acids on body temperature, serum biochemistry, serum insulin and recovery variables in healthy dogs undergoing ovariohysterectomy. Vet Rec 2018;183:191.

19. Fujita T, Okada N, Kanamori J, et al. Thermogenesis induced by amino acid administration prevents intraoperative hypothermia and reduces postoperative infectious complications after thoracoscopic esophagectomy. Dis Esophagus 2017;30:1-7.

20. Hübner M, Lovely JK, Huebner M, et al. Intrathecal analgesia and restrictive perioperative fluid management within enhanced recovery pathway: hemodynamic implications. J Am Coll Surg 2013;216:1124-34.

21. Senagore AJ, Emery T, Luchtefeld M, et al. Fluid management for laparoscopic colectomy: a prospective, randomized assessment of goal-directed administration of balanced salt solution or hetastarch coupled with an enhanced recovery program. Dis Colon Rectum 2009;52:1935-40.

22. Read TE, Brozovich M, Caushaj PF. Perioperative hypothermia during colectomy: when do patients get cold?
Tech Coloproctol 2018;22:343-6.

23. Lee HY, Kim G, Shin Y. Effects of perioperative warm socks-wearing in maintaining core body temperature of patients undergoing spinal surgery. J Clin Nurs 2018;27:1399-407.

24. Emmert A, Gries G, Wand S, et al. Association between perioperative hypothermia and patient outcomes after thoracic surgery: A single center retrospective analysis. Medicine (Baltimore) 2018;97:e0528.

25. Jildeh TR, Okoroha KR, Marshall NE, et al. The Effect of Intraoperative Hypothermia on Shoulder Arthroplasty. Orthopedics 2018;41:e523-8.

26. Jin L, Ge S, Wang H, et al. Metabolic effects of intraoperative amino acid infusion in mongrel dogs. Ann Nutr Metab 2012;61:117-25.

27. Keeling WB, Kilgo PD, Puskas JD, et al. Off-pump coronary artery bypass grafting attenuates morbidity and mortality for patients with low and high body mass index. J Thorac Cardiovasc Surg 2013;146:1442-8.

28. Matos JR, McSwain JR, Wolf BJ, et al. Examination of intra-operative core temperature in joint arthroplasty: a single-institution prospective observational study. Int Orthop 2018;42:2513-9.
Cite this article as: Jin L, Han X, Yu Y, Xu L, Wang H, Guo K. Intraoperative thermal insulation in off-pump coronary artery bypass grafting surgery: a prospective, double blind, randomized controlled, single-center study. Ann Transl Med 2020;8(19):1220. doi: 10.21037/atm-19-4571 